\title{
A Reduced-Form Rapid Economic Consequence Estimating Model: Application to Property Damage from U.S. Earthquakes
}

\author{
Nathaniel Heatwole ${ }^{1}$ and Adam Rose Re,* $^{1,2,}$ \\ ${ }^{1}$ National Center for Risk and Economic Analysis of Terrorism Events (CREATE), University of Southern California, \\ Los Angeles, CA 90089, USA \\ ${ }^{2}$ Price School of Public Policy, University of Southern California, Los Angeles, CA 90089, USA
}

\begin{abstract}
Modeling the economic consequences of disasters has reached a high level of maturity and accuracy in recent years. Methods for providing reasonably accurate rapid estimates of economic losses, however, are still limited. This article presents the case for "reduced-form" models for rapid economic consequence estimation for disasters, and specifies and statistically estimates a regression equation for property damage from significant U.S. earthquakes. Explanatory variables are of two categories: (1) hazard-related variables pertaining to earthquake characteristics; and (2) exposure-related variables pertaining to socioeconomic conditions. Comparisons to other available earthquake damage estimates indicate that our Reduced-Form Model yields reasonably good results, including several statistically significant variables that are consistent with a priori hypotheses. The article concludes with a discussion of how the research can be enhanced through the collection of data on additional variables, and of the potential for the extension of the reduced-form modeling approach to other hazard types.
\end{abstract}

Keywords earthquakes, natural hazard loss estimation, property damage, rapid estimation, reduced-form modeling, United States

\section{Introduction and Background}

Various sophisticated economic consequence modeling methods exist, including econometric and computable general equilibrium. These models have proved versatile and accurate in their estimation of the total economic impacts of a range of hazards, including both terrorist attacks and natural disasters. Specific applications include the economic consequences of 9/11 (Rose and Blomberg 2010), a radiological dispersion device ("dirty bomb") attack (Giesecke et al. 2012), an H1N1 epidemic (Dixon et al. 2010), a major earthquake (Rose, Wei, and Wein 2011), and a severe winter storm and ensuing flooding (Sue Wing, Rose, and Wein 2010). Unfortunately, these models are time-consuming to construct and operate, and

\footnotetext{
* Corresponding author. E-mail: Adam.Rose@usc.edu
}

cannot provide quick response results unless a model for a specific region or country is already in place. Moreover, their accuracy is highly dependent on that of direct loss estimates, for which there are few existing models beyond those applied to earthquakes.

The potential benefits of reduced-form rapid economic estimating models are primarily threefold (see also Chan et al. 1998; Erdik et al. 2011; Jaiswal and Wald 2011):

(1) Transparency: a single equation (or small number of equations) for economic consequence estimation, using a minimum of predictor variables and without any complicated input parameters (such as building inventories or building damage summaries);

(2) Flexibility: applicable to many different hazard situations, which might occur in a variety of different locations, and can easily be updated to incorporate new data as they become available; and

(3) Rapidity: fast speed of generating results in the immediate aftermath of a disaster event.

The combination of these factors makes the reduced-form approach accessible and attractive to a broad array of users. For example, reduced-form models might be used by emergency managers and first responders, government officials, academics and researchers, insurance firms, or even members of the public. They can be applied ex ante (in risk assessments and disaster planning), as well as ex post (for assessing the scope of a disaster event soon after it occurs, and for related decision support regarding resource allocation and resource mobilization).

To help fill this niche, and also to address the various limitations of the other models identified below, this article presents the development of a reduced-form model for property damage in significant U.S. earthquakes. This involves the use of an econometric approach that regresses the economic consequences (that is, property damage) on a set of explanatory variables, such as hazard size/intensity, population of the area affected, and health of the local economy.

The remainder of this article is organized as follows. Section 2 presents a brief summary of existing rapid loss 
estimation models for earthquakes. Section 3 identifies possible predictor variables for a Reduced-Form Model of property damage from U.S. earthquakes. In Section 4, we discuss the basic data and data refinements used in the analysis. We specify our estimating equation in Section 5, and provide summary statistics for the data used to estimate it in Section 6. We present our results in Section 7, and Section 8 presents a comparison of the results from our Reduced-Form Model with various other damage estimates from the literature for a series of out-of-sample test cases. In Section 9, we discuss broadening the loss estimation methodology to direct and indirect business interruption.

\section{Literature Review of Earthquake Rapid Damage Estimating Tools}

In the literature, various methodologies exist for providing quick earthquake loss estimates (see also the review by Erdik et al. 2011). Loayza et al. (2012) present regression equations modeling the effects of various hazard events on different types of economic growth (for example, GDP growth), including earthquakes, but do not model the damages from the event, per se. Chan et al. (1998) present regression equations modeling the (log of the) losses for 29 global earthquakes (1981-1995) at various Modified Mercalli Intensity (MMI) levels of shaking, as a function of the (log of the) GDP of the population exposed at each of these intensity levels. However, they do not examine other possible predictor variables, and U.S. earthquakes constitute a minority of their sample $(7 / 29=24 \%)$. Schumacher and Strobl (2011) use regression analysis to model earthquake losses using the GDP per capita, GDP per capita squared, area (spatial), population density of the area affected, and the energy released by the earthquake (measured in Joules), but specify these exposurerelated predictor variables using only data at the country level.

The most comprehensive rapid estimation model to date is the Federal Emergency Management Agency's "Hazards United States," or HAZUS (FEMA 2012). It consists of a complex set of damage functions and a voluminous set of data on the built environment, with an option of incorporating the user's own primary data. However, HAZUS is not accessible to all who would seek to obtain rapid loss estimates, given the high set-up costs and steep learning curve for using this software correctly. HAZUS was originally developed for earthquakes in the mid-1990s, but has been expanded to cover floods and hurricane damages in recent years, and the development of a tsunami module is currently under way. Unlike most of the other rapid estimation tools, HAZUS goes beyond property damage estimation to include direct and even indirect business interruption (BI). Direct BI estimates are derived from property damage by a set of multiplicative factors, but the calculations do take into account various types of resilience (or tactics that mute BI losses), such as business relocation and recapturing lost production at a later date.
Indirect $\mathrm{BI}$ is calculated with the use of a flexible input-output modeling approach, which is difficult to use properly for those not familiar with this economic tool. It also includes resilience tactics such as inventories and increased reliance on imports.

The Economic Commission for Latin America and the Caribbean (ECLAC 2003) provides an earthquake loss assessment methodology, but like HAZUS, requires information related to the numbers and types of damaged structures as an input. Huyck et al. (2006) use the U. S. Geological Survey's ShakeMaps (USGS 2012b) and simplified HAZUS damage functions (converted to SQL queries to reduce runtime) to rapidly estimate damages from earthquakes occurring in Southern California (including the effects on transportation flows). Their model - the Internet-based Loss Estimation Tool (INLET) - is available as a web-based tool. Unfortunately, like HAZUS, the damage functions are internal to the software, and one of their model inputs is an assessment of the building inventory affected by the event.

One of the more elaborate rapid estimating tools for earthquakes is the USGS (2012a) Prompt Assessment of Global Earthquakes for Response (PAGER) system. PAGER also provides these estimates automatically, using data from the USGS (2012b) ShakeMaps, which are generated in the minutes after an earthquake occurs. PAGER uses a loss ratio to model damages - defined as the economic damage divided by the economic exposure of the area affected, where the latter is GDP of the area affected with a subsequent correction to account for the difference between wealth (stock) and GDP (flow). This loss ratio is assumed to be log-normally distributed - with parameters that are a function of the MMI shaking level / damage outcome, and which are chosen based on empirical damage data.

When applied to U.S. earthquakes, however, PAGER is limited by its use of one set of coefficients for California earthquakes, and another set of coefficients for earthquakes occurring in all of the 49 other states (and the use of a single GDP value for the entire United States). As such, PAGER does not capture the subnational economic delineation of all U.S. earthquakes. By contrast, our Reduced-Form Model calculates the exposure data at the census tract level. PAGER also requires as an input the population exposed to each MMI level of shaking (for each of the MMI levels V and above, with all of the levels IX and above collapsed into level IX), whereas our model uses only the total population exposed to MMI level VI or above. Furthermore, we offer statistical goodness-of-fit measures to help gauge the accuracy/reliability of our estimates. Our Reduced-Form Model is also the product of "examining" (through the use of stepwise regression analysis) myriad different model forms, rather than assuming, as PAGER does, that losses are related only to GDP (corrected to account for wealth effects) and population.

Overall, we do not view our model as a competitor to PAGER, but rather as complementary to it. Both methods can be accessed rapidly to obtain either a ready estimate (in the case of PAGER), or to quickly calculate one (in the case of 
our Reduced-Form Model). The process of actually calculating the damage and the understanding of the underlying explanatory factors associated with our approach offer another valuable perspective on the important matter of earthquake loss estimation. Finally, we intend our model as a template for application to other hazard types, and to countries other than the United States, and we believe it would be easier for others to emulate for these purposes than PAGER.

Like PAGER, the OpenQuake method of the GEM Foundation (GEM 2011) suggests the use of a loss ratio to model earthquake damages (or the damage scaled by the value of the exposed assets). This loss ratio is assumed to be log-normally distributed (although other distributions - such as the beta distribution - are suggested as also potentially useful). The coefficients of this distribution (which might be determined from empirical data, analytical models, and/or expert judgment) are a function of the MMI shaking level. The current version of the OpenQuake model, however, does not include this loss estimation component, which is expected to be several years away from full development.

\section{Basic Modeling Approach}

Property damage from earthquakes is a function of hazardrelated variables pertaining to earthquake characteristics, and exposure-related variables pertaining to socioeconomic considerations (see also the references in Section 2). There are a large number of potentially influential variables, so we took a pragmatic approach of identifying major ones that were available in existing databases, or that could be obtained in other statistical compilations (and for which values would be known soon after a disaster event occurs).

\subsection{Exposure-Related Predictors}

The various exposure-related predictor variables that we examine are:

- $\boldsymbol{P O P}$ - population of the area affected, ${ }^{\mathrm{i}}$ in the year in which the earthquake occurred, using data from the U.S. Census Bureau. Superficially, population would seem to be irrelevant for our purposes, as we are modeling damage to property, and not damage to people. It is reasonable to assume, however, that population correlates with the value of property that is at risk of damage (that is, exposure).

- INCOME - total income (annual) of the area affected, in the year in which the event occurred. This is specified using data from the U.S. Bureau of Economic Analysis (BEA 2012), and adjusted to 2011\$ using the Consumer Price Index (CPI). While population contains no direct monetary information, income does. At the same time, income is an imperfect measure of exposure to property damage. For example, an area with a large percentage of affluent retirees may have a relatively low income, yet also contain much valuable property at risk of being damaged by earthquakes.
- $\boldsymbol{A R E A}$ - area of the region affected, obtained from the U.S. Census Bureau. Both population and income (above) assess exposure, but these metrics are limited by their lack of spatial (or density) information. For example, a given population may be spread out over a large area, thereby presumably reducing the (aggregate) exposure.

- PRE-1985 - binary variable for events occurring before the year 1985. The purpose of this variable is to control for temporal changes in exposure, most notably those associated with changes in building codes and building materials. A dividing year of 1985 was chosen because it corresponds to an approximation of building code revisions; coincidentally, it divides our dataset into roughly two equal groups. There is, however, potentially enormous temporal variation in the exposure, and a binary indicator is only a crude assessment of this.

- $\boldsymbol{C A}$ - binary variable for events occurring in the state of California. The purpose of this variable is twofold: (1) more of the events in our dataset occurred in California than in any other state (see Section 4.1); and (2) California's seismic-related building code provisions are considerably more rigorous than those of other states. The variable implicitly assumes, however, that all events in California can be treated as equivalent. Yet because California is such a large and geologically diverse state, sizeable intrastate variation in exposure may exist.

Using the various predictor variables above, we define three additional exposure-related interaction terms:

- $\boldsymbol{P C I}$ - per capita income, or total income (INCOME) divided by population $(P O P)$. While income and population both independently reflect economic exposure, the ratio of the two quantities might capture any combined effects.

- POP DEN - population density, or total population $(P O P)$ divided by land area $(A R E A)$. This variable accounts for the fact that the population affected by the event is not clustered all at a single point, but rather spread over a region.

- INC DEN - ratio of total income (INCOME) to land area $(A R E A)$, or the income "density" of the area affected. Similar to population density (above), this variable considers the fact that the income is distributed spatially.

\subsection{Hazard-Related Predictors}

The various hazard-related predictors examined are:

- $\boldsymbol{M A G}$ - earthquake magnitude, or the energy released by the fault rupture, obtained from the National Geophysical Data Center (NGDC 2011). The earthquake's magnitude, while informative, also has limitations. For example, the magnitude number provides only limited 
information about the duration of the shaking. Moreover, the translation from the magnitude to the forces exerted on (that is, damage to) structures at the surface is nontrivial, and depends on numerous factors (including soil type).

- DEPTH - distance (into the ground) of the earthquake hypocenter (that is, the location where the fault rupture begins), also obtained from NGDC. This is the separation between the earthquake hypocenter and its counterpart at the surface, the epicenter. The depth conceivably influences property damages, in that deeper earthquakes may be less capable of inflicting damage to structures (which are located at the surface). At the same time, the straight line depth into the ground may be of limited explanatory power, as the damages are also greatly influenced by the particular characteristics of the medium (that is, soil) through which the seismic waves travel.

- $\boldsymbol{D} \boldsymbol{X}$ - latitude and longitude data for the earthquake epicenter are available from NGDC, and the latitude and longitude of the population centroids for all U.S. census tracts were obtained from the U.S. Census Bureau (2012a). The epicentral distance between these two points $(D X)$ was then computed using a spreadsheet formula. ${ }^{\text {ii }}$ The greater the value of $D X$, presumably the less the exposure. The centroid of population, however, is a summary statistic (that is, an average), and much information is necessarily lost in the process of that summation. For example, few people (property) may be present in the vicinity of the population centroid.
And using the various hazard-related predictors above, we define two hazard-related interaction terms:

- $\boldsymbol{X}$ - hypocentral distance, or the distance from the hypocenter to the population centroid of the affected area, as determined using the Pythagorean Theorem. The farther the population centroid from the hypocenter, presumably the less the potential for damage. However, this variable is limited by its dependence on the quantities $D E P T H$ and $D X$, each of which singularly has limitations (see above).

- $(\boldsymbol{M A G} / \boldsymbol{X})$ - magnitude scaled (divided) by the hypocenter-population centroid separation $(X)$. The quantity $X$ is placed in the denominator on the basis that the property damage is a decreasing function of $X$. In essence, this variable assumes that the earthquake (which is of intensity $M A G$ ) "acts" through a distance $X$ to impact the (population center of the) area affected. While the $M A G$ and $X$ variables might each individually relate to exposure, their combination (interaction) may allow for an even more complete assessment. ${ }^{\text {iii }}$

All of the variables used in the analysis are summarized in Table 1.

\section{Regression Model Data}

We begin this estimation using data on property damage from earthquakes from the Spatial Hazard Events and Losses Database for the United States (SHELDUS). SHELDUS was developed by Susan Cutter and Dennis Mileti-two leading

Table 1. Summary of all variables used in the analysis

\begin{tabular}{|c|c|c|c|c|}
\hline \multicolumn{2}{|l|}{ Variable } & \multirow[t]{2}{*}{ Description } & \multirow[t]{2}{*}{ Units } & \multirow[t]{2}{*}{ Data Source(s) } \\
\hline Type & Notation & & & \\
\hline \multirow[t]{3}{*}{ Dependent } & $P D_{\text {low }}$ & Lower bound of property damage & $2011 \$$ & various (see Section 4.2) \\
\hline & $P D_{\text {average }}$ & Average property damage & $2011 \$$ & various \\
\hline & $P D_{\text {high }}$ & Upper bound of property damage & $2011 \$$ & various \\
\hline Exposure-Related & POP & Population affected & persons & BEA (2012) \\
\hline \multirow[t]{7}{*}{ Predictors } & INCOME & Total income of population affected & $2011 \$$ & BEA (2012) \\
\hline & $A R E A$ & Land area affected & $\mathrm{km}^{2}$ & U.S. Census Bureau (2012b) \\
\hline & $P C I$ & Ratio of total income to population; per capita income & $2011 \$$ & calculated $^{\dagger}$ \\
\hline & POPDEN & Ratio of population to land area; spatial density of population & persons $/ \mathrm{km}^{2}$ & calculated $^{\dagger}$ \\
\hline & $I N C D E N$ & Ratio of total income to land area; spatial "density" of income & $2011 \$ / \mathrm{km}^{2}$ & calculated ${ }^{\dagger}$ \\
\hline & $C A$ & Indicates if event occurred in the state of California & binary & SHELDUS (2011) \\
\hline & $P R E-1985$ & Indicates if event occurred prior to the year 1985 & binary & SHELDUS (2011) \\
\hline \multirow{6}{*}{$\begin{array}{l}\text { Hazard-Related } \\
\text { Predictors }\end{array}$} & $M A G$ & Earthquake magnitude & Richter & NGDC (2011) \\
\hline & DEPTH & Separation (into ground) between epicenter to hypocenter & $\mathrm{km}$ & NGDC (2011) \\
\hline & $D X$ & Separation (along ground) between epicenter and population & $\mathrm{km}$ & NGDC (2011) \\
\hline & & centroid of area affected & & U.S. Census Bureau (2012a) \\
\hline & $\boldsymbol{X}$ & $\begin{array}{l}\text { Separation (through ground) between hypocenter and population } \\
\text { centroid of area affected }\end{array}$ & $\mathrm{km}$ & calculated $^{\dagger}$ \\
\hline & $(M A G / X)$ & $\begin{array}{l}\text { Earthquake magnitude scaled by the separation between the } \\
\text { hypocenter and the population centroid of area affected }\end{array}$ & Richter/km & calculated ${ }^{\dagger}$ \\
\hline
\end{tabular}


hazard researchers - and although SHELDUS is limited to natural disasters, it is very extensive, covering all 50 U.S. states and going back decades. Our analysis uses data from SHELDUS version 9.0 (SHELDUS 2011). We then identified some limitations of the SHELDUS database and refined it for use in our statistical analysis, and the preliminary results for this individual hazard area are promising.

From the SHELDUS database, various data are available, including the date of the event, counties affected, and property damage that resulted (in both nominal and inflationadjusted terms). ${ }^{\text {iv }}$ SHELDUS also lists other data related to each event (such as estimated crop damage), but these other data are not relevant to our purposes. Note also that the damages in SHELDUS are conservative, in that it reports the lowest estimated damage that is believed to be associated with the event (although as we discovered, the SHELDUS estimates are not always the lowest available estimate- see Section 6).

\subsection{Earthquake Events in SHELDUS}

We reviewed the SHELDUS database for all earthquake events:

- which resulted in at least $P D=\$ 50,000$ in total property damage (2011\$, sum over all counties affected);

- which were not the result of a volcanic eruption (as in the case of the Mt. St. Helens eruption in May 1980). However, we do include events where a volcanic eruption occurred as a result of an earthquake; and

- for which hazard intensity data (for example, magnitude) and exposure data (for example, population of area affected) can be obtained (SHELDUS does not provide these data).

Determining which rows in SHELDUS were associated with each earthquake event was straightforward, as all of the events were "clustered" by date and by county. We did not encounter any cases in SHELDUS where earthquake property damages are listed for two or more non-adjacent counties on the same date, nor did we encounter instances of the same earthquake event causing damage in more than one state.

The final dataset consisted of $n=40$ earthquake observations, which took place in eight states: California (26 events); Hawaii (five events); Alaska, Oregon, and Idaho (two events each); and Washington, Nevada, and Kentucky (one event each). As such, our dataset is somewhat California-centric (65\% of the events). Our approach to damage estimation is highly empirical, and California experiences many earthquakes, resulting in a high proportion of the available damage data coming from California. In less than 20 percent of the earthquake events in our dataset (7/40) did the damages affect more than a single county. For virtually all of the earthquake events in SHELDUS, county-specific property damage data seem not to be available, in that it appears SHELDUS merely portioned the total damage equally among all of the counties affected-something which, for the purposes of our analysis, is seemingly unnecessary.

\subsection{Earthquake Property Damage Estimates from the Literature}

The property damage data in SHELDUS are limited by the facts that: (1) SHELDUS is county-oriented, yet the damages from earthquakes tend to be much more localized than the area of an entire U.S. county; and (2) SHELDUS reports only a point estimate of the damage. To address these limitations, we went directly to the primary sources on which SHELDUS relied, as well as other literature sources, and collected all available property damage estimates for each of the 40 earthquake events in our sample.

We utilized all credible observations, and located a total of 118 property damage estimates (average of 3.1 observations per event). More than half of these data (54\%) came from one of two sources: the USGS publication Seismicity of the United States, 1568-1989 (Stover and Coffman 1993), and the Significant Earthquake Database of the NGDC (2011). Most of the remaining sources were either state and federal government agencies, or articles in academic or professional journals.

For each earthquake event, the minimum, average, and maximum estimated property damages are denoted $P D_{\text {low }}$, $P D_{\text {average, }}$ and $P D_{\text {high }}$, respectively. In cases where only a single damage estimate was located, all three of the $P D$ variables are equal. And if for a particular event two or more of the damage estimates were equivalent (but came from different sources), all of these were considered a single damage estimate for the computation of $P D_{\text {average }}$.

In instances where a source specifies a range of damage estimates, we assumed that the distribution of damages was log-normal (see also Section 2). The parameters (that is, mean and standard deviation) of this log-normal distribution were then set such that the 2.5th and 97.5th percentiles of the distribution are equal to the lower and upper extremities of the damage range, respectively (in essence, assuming that the range represents the 95 percent confidence interval of damage). The average damage value $\left(P D_{\text {average }}\right)$ in this case is then the expected value of the log-normal distribution. In the event that the lower end of the damage range was zero, we recoded this as $P D=\$ 50,000$ (see inclusion criteria in Section 4.1).

\subsection{Specification of the Exposure-Related Predictor Variables}

Rather than basing the estimation of the exposure-related variables (for example, population, income) on data from the county level (as might be suggested by the way that SHELDUS is structured), we collected these data at a finer geographic resolution, at the census tract (rather than the county) level.

The area affected by each event was determined using the USGS (2012b) ShakeMaps, which contain color-coded spatial estimates of shaking intensity, according to the levels of the MMI. For each of the 40 earthquake events in our 
dataset, polygons were drawn on the ShakeMaps: (1) so as to reasonably cover the area that experienced a shaking intensity of MMI VI (indicating "strong" shaking and "light" damage potential) or greater; and (2) so that the latitude and longitude coordinates of each edge of the polygon were at even 0.25 degree increments. The coordinates of these polygons were then entered into the ArcGIS software program (ESRI 2010), which selected all census tracts any portion of which was contained in a given polygon. This collection of census tracts was then defined as the area affected by the earthquake.

The exposure-related data in ArcGIS (for example, income, population) derive from the American Community Survey of the U.S. Census Bureau (2010). Accordingly, these values were adjusted to the year of the earthquake. This was done by considering the percentage change in each quantity at the county level between the year that the earthquake occurred and the year 2010, as reported by the BEA, and with consideration of the number of people affected in each county (sum over all census tracts). Similarly, the $D X$ variable in this case was computed for each census tract affected, and then combined using a population-weighted average by census tract.

So while our model was formulated using exposurerelated variables specified at the census tract-level, exposure data need not be available at this high a level of spatial resolution to use it. This is because the Reduced-Form Model is intended to be a preliminary rapid estimating tool (see also the modest model fits in Section 7), and not to provide definitive loss estimates. Accordingly, data at the county level (or county-level data that has been apportioned down to the census tract level) should suffice in many application areas for the Reduced-Form Model.

\section{Regression Model Form}

It is customary to first consider an ordinary linear regression model of the form

$$
P D=k_{0}+k_{1} \cdot X_{1}+k_{2} \cdot X_{2}+\cdots+k_{c} \cdot X_{c}+\varepsilon \quad \text { Eq. } 1
$$

where the $k$-values are the regression coefficients, $c$ denotes the number of predictor variables, and the error term, $\varepsilon$, is normally independent and identically distributed with zero mean and standard deviation $\sigma_{\varepsilon}$.

In a regression model, while the predictor variables need not be normally distributed, ideally the dependent variable should be reasonably so, especially if the number of predictor variables is large (per the central limit theorem). In our case, however, the dependent variable (property damage) is highly skewed (note the large difference between the average and median values in Table 2), so we transform it by taking the natural log, which considerably improves the normality.

The use of a logged dependent variable, however, complicates the interpretation of the regression coefficients (relative to the case of non-logged dependent variables). For this reason, we also transform all of the predictor quantities (both hazard- and exposure-related, but not the binary variables) by taking their natural logs, thereby yielding a regression model of the form

$\ln (P D)=k_{0}+k_{1} \cdot \ln \left(X_{1}\right)+k_{2} \cdot \ln \left(X_{2}\right)+\cdots+k_{c} \cdot \ln \left(X_{c}\right)+\varepsilon$ Eq. 2

or more concisely as

$$
\ln (P D)=\left[\sum_{i=0}^{c} k_{i} \cdot \ln \left(X_{i}\right)\right]+\varepsilon
$$

Eq. 3

\begin{tabular}{|c|c|c|c|c|c|c|}
\hline \multicolumn{2}{|l|}{ Variable } & \multirow[t]{2}{*}{ Average } & \multirow[t]{2}{*}{ Median } & \multirow[t]{2}{*}{ Standard Deviation } & \multirow[t]{2}{*}{ Minimum } & \multirow[t]{2}{*}{ Maximum } \\
\hline Type & Notation & & & & & \\
\hline \multirow[t]{5}{*}{ Dependent-Related } & $P D_{\text {low }}$ & $\$ 890 \mathrm{M}$ & $\$ 18 \mathrm{M}$ & $\$ 3.5 \mathrm{~B}$ & $\$ 50,000$ & $\$ 20 \mathrm{~B}$ \\
\hline & $P D_{\text {average }}$ & $\$ 1.7 \mathrm{~B}$ & $\$ 23 \mathrm{M}$ & $\$ 7.8 \mathrm{~B}$ & $\$ 440,000$ & $\$ 50 \mathrm{~B}$ \\
\hline & $P D_{\text {high }}$ & $\$ 2.5 \mathrm{~B}$ & $\$ 25 \mathrm{M}$ & $\$ 11 \mathrm{~B}$ & $\$ 1.7 \mathrm{M}$ & $\$ 67 \mathrm{~B}$ \\
\hline & No. $P D$ Observations & 3.1 & 3 & 1.3 & 1 & 8 \\
\hline & SPREAD $^{\dagger}$ & $55 \%$ & $30 \%$ & $75 \%$ & $0 \%$ & $380 \%$ \\
\hline \multirow{7}{*}{$\begin{array}{l}\text { Exposure-Related } \\
\text { Predictor }\end{array}$} & POP & $1.1 \mathrm{M}$ & 98,000 & $2.7 \mathrm{M}$ & 11,000 & $13 \mathrm{M}$ \\
\hline & INCOME & $\$ 27 \mathrm{~B}$ & $\$ 1.7 \mathrm{~B}$ & $\$ 62 \mathrm{~B}$ & $\$ 79 \mathrm{M}$ & $\$ 310 \mathrm{~B}$ \\
\hline & $A R E A$ & $21,000 \mathrm{~km}^{2}$ & $11,000 \mathrm{~km}^{2}$ & $35,000 \mathrm{~km}^{2}$ & $560 \mathrm{~km}^{2}$ & $200,000 \mathrm{~km}^{2}$ \\
\hline & PCI & $\$ 22,000$ & $\$ 22,000$ & $\$ 7200$ & $\$ 6900$ & $\$ 39,000$ \\
\hline & POP DEN & $130 / \mathrm{km}^{2}$ & $11 / \mathrm{km}^{2}$ & $300 / \mathrm{km}^{2}$ & $0.055 / \mathrm{km}^{2}$ & $1600 / \mathrm{km}^{2}$ \\
\hline & $I N C D E N$ & $\$ 2.9 \mathrm{M} / \mathrm{km}^{2}$ & $\$ 240,000 / \mathrm{km}^{2}$ & $\$ 6.5 \mathrm{M} / \mathrm{km}^{2}$ & $\$ 1300 / \mathrm{km}^{2}$ & $\$ 35 \mathrm{M} / \mathrm{km}^{2}$ \\
\hline & No. Census Tracts & 310 & 30.5 & 710 & 3 & 3300 \\
\hline \multirow{5}{*}{$\begin{array}{l}\text { Hazard-Related } \\
\text { Predictor }\end{array}$} & $M A G$ & 6.2 & 6.1 & 0.68 & 5.0 & 7.9 \\
\hline & DEPTH & $14 \mathrm{~km}$ & $10 \mathrm{~km}$ & $12 \mathrm{~km}$ & $1.0 \mathrm{~km}$ & $52 \mathrm{~km}$ \\
\hline & $D X$ & $30 \mathrm{~km}$ & $25 \mathrm{~km}$ & $25 \mathrm{~km}$ & $3.8 \mathrm{~km}$ & $130 \mathrm{~km}$ \\
\hline & $X$ & $35 \mathrm{~km}$ & $27 \mathrm{~km}$ & $25 \mathrm{~km}$ & $11 \mathrm{~km}$ & $135 \mathrm{~km}$ \\
\hline & $(M A G / X)$ & $0.25 / \mathrm{km}$ & $0.24 / \mathrm{km}$ & $0.12 / \mathrm{km}$ & $0.045 / \mathrm{km}$ & $0.54 / \mathrm{km}$ \\
\hline
\end{tabular}

Table 2. Descriptive statistics related to property damage in significant U.S. earthquakes $(n=40)$

Note: ${ }^{\dagger}$ Difference between $P D_{\text {low }}$ and $P D_{\text {high }}$, multiplied by $100 \%$, and then divided by $P D_{\text {average }}$. 
Accordingly, our model is fundamentally non-linear, in that logged variables are present on both sides of the equals sign. And with log-log regression models of the form of equations 2 and 3, the elasticities of property damage with respect to the variable $X_{i}$ (when controlling for the effects of all of the other predictors) is simply the value of the regression coefficient associated with $X_{i}$, or $k_{i}$.

\section{Descriptive Statistics and Scatter Plots}

Various descriptive statistics related to the quantities listed in Table 1 are given in Table 2. Interestingly, although SHELDUS purportedly reports the lower-bound estimate of the damage, across the $n=40$ events, the lowest property damage estimate from the literature is, on average, 27 percent less than the value of damage reported in SHELDUS.
A scatter plot of the average property damage estimate $\left(P D_{\text {average }}\right)$ as a function of the chronological order of the earthquake is given in Figure 1 (note that the $Y$-axis is a log scale). Figure 1 indicates no marked temporal variation, although the variance may be increasing somewhat.

A plot of $P D_{\text {average }}$ as a function of the earthquake magnitude is given in Figure 2, where the two single most damaging events (Northridge/1994 and Loma Prieta/1989 - both in California) are labeled for reference. While indicating a slightly upward trend in the data, Figure 2 also shows the limitations of using the magnitude number to predict property damage (see Section 3.2). For example, there are cases of roughly the same level of property damage being sustained at both relatively low magnitude values, and also at relatively high magnitudes values. Similarly, there are instances of both relatively low and relatively high property damage values occurring around the same small range of magnitude numbers.

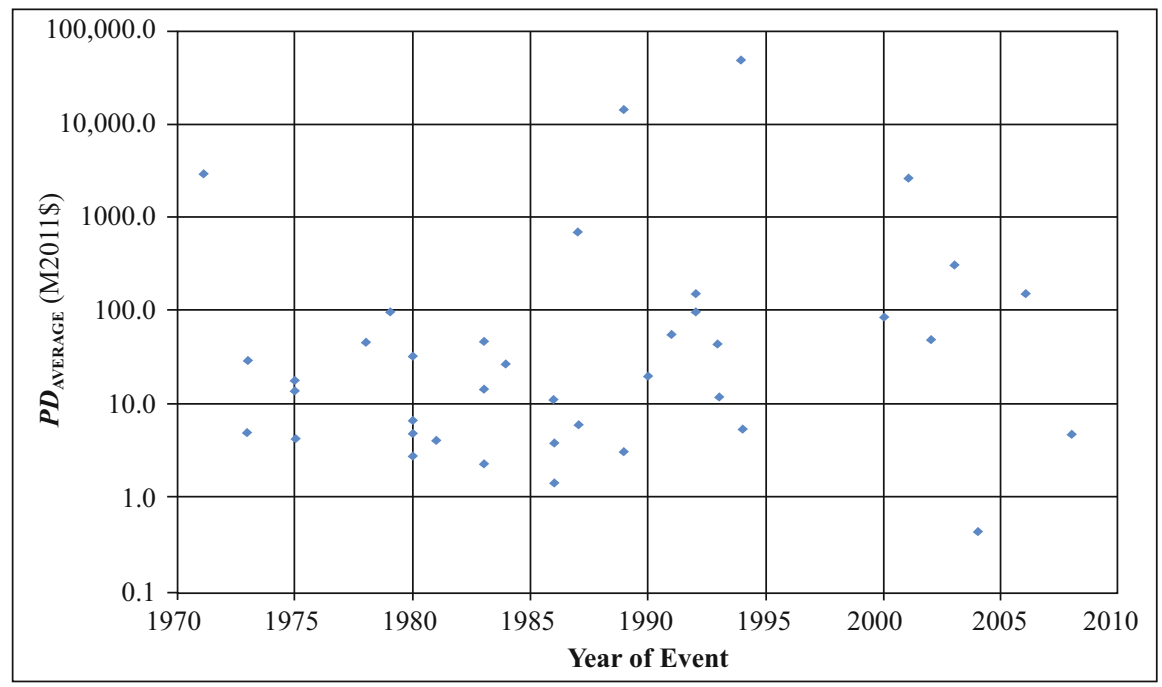

Figure 1. Plot of property damage (average value) from significant U.S. earthquakes over time ( $n=40)$, indicating no marked temporal variation

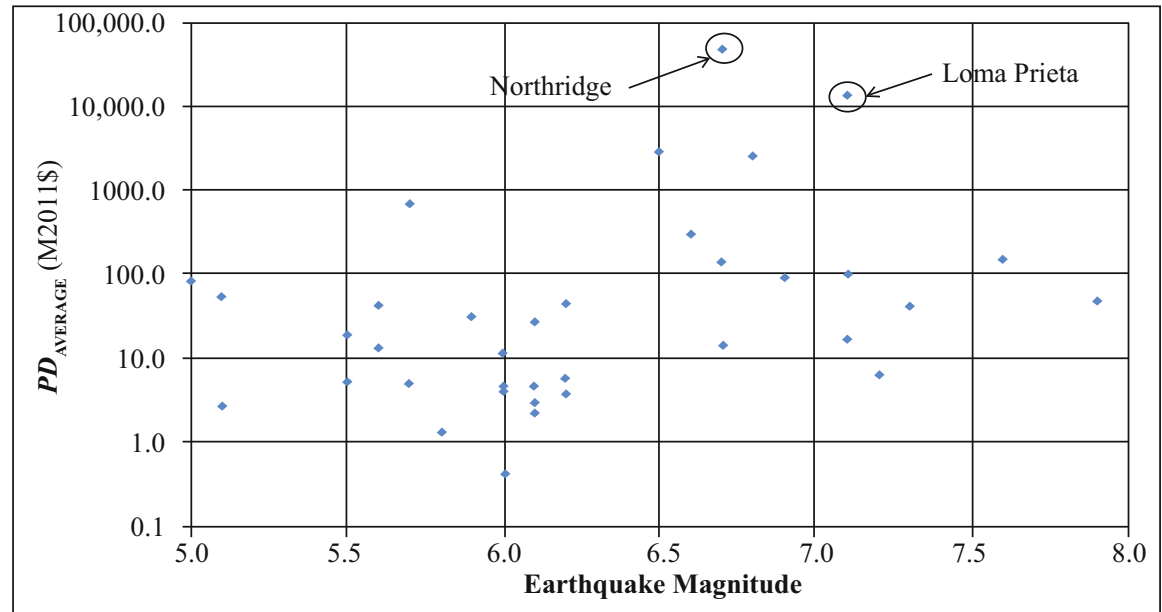

Figure 2. Plot of property damage (average value) from significant U.S. earthquakes, as a function of the earthquake magnitude $(n=40)$, with the two single most damaging events (Northridge/1994 and Loma Prieta/1989—both in California) noted for reference 
Plots of $P D_{\text {average }}$ as a function of the population and income of the area affected are given in Figures 3 and 4, respectively. All of the axes in Figures 3 and 4 are log scales, and the data in each case follow a generally upwards trend, suggesting a power function relationship between the $Y$ - and $X$-variables in each case.

\section{Results of the Regression Analyses}

At each level of property damage ( $P D_{\text {low }}, P D_{\text {average }}$, and $\left.P D_{\text {high }}\right)$, a stepwise regression analysis was undertaken using the Matlab software program (MathWorks 2011). Stepwise regression is an iterative, heuristic-based procedure for selecting the particular regression equation (that is, combination of predictor variables) that maximizes the model's adjusted $R$-squared value. We used forwards stepwise regression, with the $p$-values for inclusion to and exclusion from the model set to 0.05 and 0.10 , respectively (the default values in
Matlab). Backwards stepwise regression is outside the scope of this article but, based on the reviewer's comments, will be one of our first priorities in upcoming research.

Stepwise regression, however, has various limitations. For example, because stepwise regression is heuristic-based, the routine is not guaranteed to select the model with literally the highest adjusted $R$-squared value (although it will generally do quite well). Stepwise regression has also been criticized for being overly utilitarian, by selecting variables only to improve the model fit, potentially leading to data over-fitting and regression models that appear very ad hoc. Accordingly, the output from any stepwise regression procedure should be carefully reviewed, being mindful that various other (and potentially more meaningful or intuitive) combinations of the predictor variables may exist that will yield nearly as good a fit to the data.

The "raw" (or unchanged) stepwise regression output is given in Table 3. For $P D_{\text {low }}$ and $P D_{\text {average }}$, the stepwise procedure selected the $P O P$ and $M A G$ variables for inclusion in the

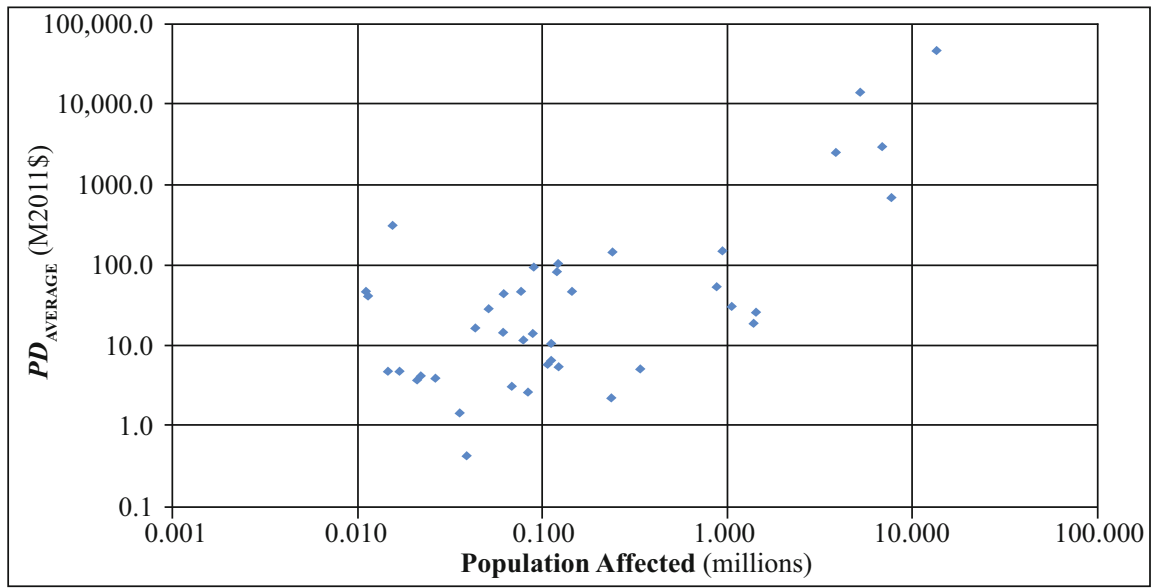

Figure 3. Plot of property damage (average value) from significant U.S. earthquakes ( $n=40$ ), as a function of the population affected by the event

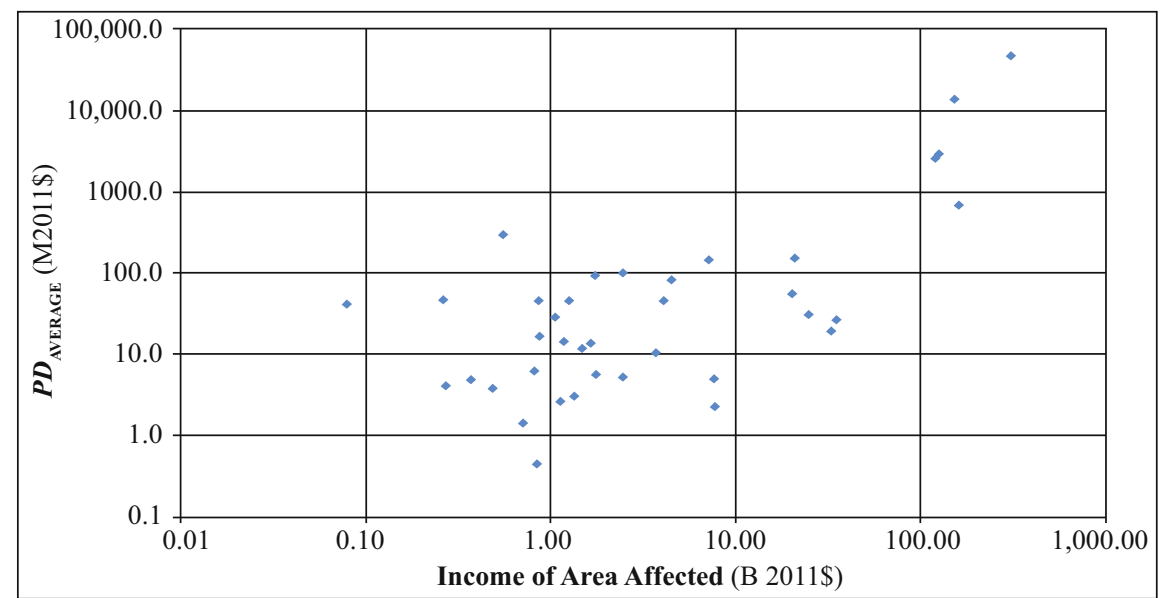

Figure 4. Plot of property damage (average value) from significant U.S. earthquakes ( $n=40$ ), as a function of the total income of the area affected 
model. For $P D_{\text {high }}$, the variables selected are slightly different, with INCOME being chosen instead of POP. So for completeness, we also regressed all of the property damage estimates (low, average, and high) on $M A G$ and INCOME (Table 4), and also on $M A G$ and $P O P$ (Table 5). The results of these regressions (given in Tables 4 and 5) are generally similar to the raw stepwise regression results (Table 3).

Across all of the regression models, the adjusted R-squared values are reasonably good for cross-sectional analysis, at 0.58-0.61, and all of the coefficients (excluding some of the intercepts) are highly significant. In all cases, the largest coefficient values (in absolute value; excluding the intercepts) are those for $M A G$, with elasticities of 8.0-9.2 percent. This indicates that every 1 percent increase in the magnitude causes an 8.0-9.2 percent increase in $P D$. The exposure-related coefficient values (for the $P O P$ and INCOME variables) range from $0.84-0.93$ percent, indicating that property damage increases slower-than-linearly in each of these quantities. Collectively, these results suggest that earthquake property damages depend much more on the physical (hazard) variables than on the economic (exposure) variables. Establishing causality here, however, is difficult, as our property damage model is highly empirical, that is, it only allows us to assess if the predictions of our model are consistent with various a priori hypotheses.

We also performed a stepwise regression on the SHELDUS earthquake damage estimates, this time with the predictor variables defined at the county level rather than the census tract level (since SHELDUS is county-based). In this case (results not shown), the stepwise procedure selected the INCOME, MAG, and DX variables, with all of these coefficients highly significant. However, the model fit in this case is not quite as good as for the models based on literature damage estimates (adjusted $R$-squared of 0.53 ).

In the remainder of our analysis, we use the regression equations in Table 4, which use $M A G$ and INCOME as predictors. We use $I N C O M E$ in place of $P O P$ because income is an economic variable, whereas population is not (see Section 3). However, the regression models in Table 5 can be used in

Table 3. Raw (unmodified) stepwise regression results $(n=40)$

\begin{tabular}{|c|c|c|c|c|c|}
\hline \multirow{2}{*}{$\begin{array}{l}\text { Dependent } \\
\text { Variable }\end{array}$} & \multicolumn{2}{|c|}{ Predictor Variable } & \multirow[t]{2}{*}{ Coefficient } & \multirow[t]{2}{*}{$p$-value } & \multirow{2}{*}{$\begin{array}{c}\text { Adjusted } \\
\qquad R^{2}\end{array}$} \\
\hline & Type & Notation & & & \\
\hline \multirow[t]{3}{*}{$\ln \left(P D_{\text {low }}\right)$} & Intercept & - & -8.7 & $p=0.07$ & 0.58 \\
\hline & Exposure & $\ln (\boldsymbol{P O P})$ & 0.93 & $p<0.001$ & $\left(\sigma_{\varepsilon}=1.6\right)$ \\
\hline & Hazard & $\ln (\boldsymbol{M A G})$ & 8.0 & $p=0.002$ & \\
\hline \multirow[t]{3}{*}{$\ln \left(P D_{\text {average }}\right)$} & Intercept & - & -8.9 & $p=0.06$ & 0.60 \\
\hline & Exposure & $\ln (\boldsymbol{P O P})$ & 0.90 & $p<0.001$ & $\left(\sigma_{\varepsilon}=1.5\right)$ \\
\hline & Hazard & $\ln (M A G)$ & 8.4 & $p<0.001$ & \\
\hline \multirow[t]{3}{*}{$\ln \left(P D_{\text {ligh }}\right)$} & Intercept & - & -18 & $p=0.001$ & 0.61 \\
\hline & Exposure & $\ln (\boldsymbol{I N C O M E})$ & 0.84 & $p<0.001$ & $\left(\sigma_{\varepsilon}=1.5\right)$ \\
\hline & Hazard & $\ln (\boldsymbol{M A G})$ & 9.2 & $p<0.001$ & \\
\hline
\end{tabular}

Note: Coefficient values in bold are significant at the 0.05 level.
Table 4. Regression results when using the earthquake magnitude and the income of the area affected as predictor variables $(n=40)$

\begin{tabular}{|c|c|c|c|c|c|}
\hline \multirow{2}{*}{$\begin{array}{l}\text { Dependent } \\
\text { Variable }\end{array}$} & \multicolumn{2}{|c|}{ Predictor Variable } & \multirow[t]{2}{*}{ Coefficient } & \multirow[t]{2}{*}{$p$-value } & \multirow{2}{*}{$\begin{array}{c}\text { Adjusted } \\
R^{2}\end{array}$} \\
\hline & Type & Notation & & & \\
\hline \multirow[t]{3}{*}{$\ln \left(P D_{\text {low }}\right)$} & Intercept & - & -18 & $p=0.002$ & 0.59 \\
\hline & Exposure & $\ln (\boldsymbol{I N C O M E})$ & 0.87 & $p<0.001$ & $\left(\sigma_{\varepsilon}=1.6\right)$ \\
\hline & Hazard & $\ln (M A G)$ & 8.5 & $p=0.001$ & \\
\hline \multirow[t]{3}{*}{$\ln \left(P D_{\text {average }}\right)$} & Intercept & - & -18 & $p=0.001$ & 0.61 \\
\hline & Exposure & $\ln (I N C O M E)$ & 0.85 & $p<0.001$ & $\left(\sigma_{\varepsilon}=1.5\right)$ \\
\hline & Hazard & $\ln (M A G)$ & 8.9 & $p<0.001$ & \\
\hline \multirow[t]{3}{*}{$\ln \left(P D_{\text {high }}\right)$} & Intercept & - & -18 & $p=0.001$ & 0.61 \\
\hline & Exposure & $\ln (\boldsymbol{I N C O M E})$ & 0.84 & $p<0.001$ & $\left(\sigma_{\varepsilon}=1.5\right)$ \\
\hline & Hazard & $\ln (\boldsymbol{M} A \boldsymbol{G})$ & 9.2 & $p<0.001$ & \\
\hline
\end{tabular}

Note: Coefficient values in bold are significant at the 0.05 level.

cases where only population (and not income) data are available. Note that the predictions of these various regression equations can be non-monotonic, in that there are certain combinations of the predictor variables that can result in $P D_{\text {low }}>P D_{\text {average }}, P D_{\text {average }}>P D_{\text {high }}$, or even $P D_{\text {low }}>P D_{\text {high }}$. The particular combinations of values for the predictor variables that would bring about these outcomes, however, are generally unlikely to occur in actuality. For example, if an earthquake affects an area that has an income of $\$ 10$ billion, for $P D_{\text {low }}$ to exceed $P D_{\text {average }}$, the earthquake's magnitude must be less than about $3.2-a$ value which is outside the range of magnitude for our 40 sample earthquake dataset (see Table 2).

Table 6 summarizes the results of various analyses related to the regression fits and regression residuals for the ReducedForm Models chosen for use in the remainder of our analysis. In essence, Table 6 summarizes the information that would be contained in many different residual plots. Table 6 indicates that for all of the property damage variables, the best-fit lines for the plots of the predicted versus actual (that is, observed)

Table 5. Regression results when using the earthquake magnitude and the population of the area affected as predictor variables $(n=40)$

\begin{tabular}{|c|c|c|c|c|c|}
\hline \multirow{2}{*}{$\begin{array}{l}\text { Dependent } \\
\text { Variable }\end{array}$} & \multicolumn{2}{|c|}{ Predictor Variable } & \multirow[t]{2}{*}{ Coefficient } & \multirow[t]{2}{*}{$p$-value } & \multirow{2}{*}{$\begin{array}{c}\text { Adjusted } \\
\qquad R^{2}\end{array}$} \\
\hline & Type & Notation & & & \\
\hline \multirow{3}{*}{$\ln \left(P D_{\text {low }}\right)$} & Intercept & - & -8.7 & $p=0.07$ & 0.58 \\
\hline & Exposure & $\ln (\boldsymbol{P O P})$ & 0.93 & $p<0.001$ & $\left(\sigma_{\varepsilon}=1.6\right)$ \\
\hline & Hazard & $\ln (\boldsymbol{M A G})$ & 8.0 & $p=0.002$ & \\
\hline \multirow[t]{3}{*}{$\ln \left(P D_{\text {average }}\right)$} & Intercept & - & -8.9 & $p=0.06$ & 0.60 \\
\hline & Exposure & $\ln (\boldsymbol{P O P})$ & 0.90 & $p<0.001$ & $\left(\sigma_{\varepsilon}=1.5\right)$ \\
\hline & Hazard & $\ln (M A G)$ & 8.4 & $p<0.001$ & \\
\hline \multirow[t]{3}{*}{$\ln \left(P D_{\text {high }}\right)$} & Intercept & - & -8.9 & $p=0.06$ & 0.60 \\
\hline & Exposure & $\ln (\boldsymbol{P O P})$ & 0.88 & $p<0.001$ & $\left(\sigma_{\varepsilon}=1.5\right)$ \\
\hline & Hazard & $\ln (\boldsymbol{M} \boldsymbol{A} \boldsymbol{G})$ & 8.7 & $p<0.001$ & \\
\hline
\end{tabular}

Note: Coefficient values in bold are significant at the 0.05 level. 
Table 6. Summary of the analysis of the regression fit and residuals (error term)

\begin{tabular}{|c|c|c|c|c|}
\hline \multicolumn{2}{|c|}{ Dependent Variable } & $\ln \left(P D_{\text {low }}\right)$ & $\ln \left(P D_{\text {average }}\right)$ & $\ln \left(P D_{\text {high }}\right)$ \\
\hline \multicolumn{2}{|c|}{$\begin{array}{l}\text { Mean of Residuals } \\
\text { Normality of Residuals }{ }^{\dagger}\end{array}$} & $\begin{array}{l}-\left(8.9 \times 10^{-16}\right) \\
p=0.90\end{array}$ & $\begin{array}{l}-\left(1.9 \times 10^{-15}\right) \\
p=0.59\end{array}$ & $\begin{array}{l}\left(1.5 \times 10^{-15}\right) \\
p=0.37\end{array}$ \\
\hline $\begin{array}{l}\text { Predicted vs. } \\
\text { Actual }\end{array}$ & Intercept & $\begin{array}{l}6.6 \\
{[3.8,9.3]}\end{array}$ & $\begin{array}{l}6.3 \\
{[3.6,9.1]}\end{array}$ & $\begin{array}{l}6.4 \\
{[3.6,9.2]}\end{array}$ \\
\hline Best-Fit Line & Slope & $\begin{array}{l}0.61 \\
{[0.45,0.77]}\end{array}$ & $\begin{array}{l}0.63 \\
{[0.48,0.79]}\end{array}$ & $\begin{array}{l}0.63 \\
{[0.48,0.79]}\end{array}$ \\
\hline $\begin{array}{l}\text { Residuals vs. } \\
\text { Predicted }\end{array}$ & & $\begin{array}{l}<0.001 \\
{[-4.5,4.5]}\end{array}$ & $\begin{array}{l}<0.001 \\
{[-4.3,4.3]}\end{array}$ & $\begin{array}{l}<0.001 \\
{[-4.4,4.4]}\end{array}$ \\
\hline Best-Fit Line & Slope & $\begin{array}{l}<0.001 \\
{[-0.26,0.26]}\end{array}$ & $\begin{array}{l}<0.001 \\
{[-0.25,0.25]}\end{array}$ & $\begin{array}{l}<0.001 \\
{[-0.25,0.25]}\end{array}$ \\
\hline $\begin{array}{l}\text { Residuals vs. } \\
\text { Actual }\end{array}$ & Intercept & $\begin{array}{l}-6.6 \\
{[-9.3,-3.8]}\end{array}$ & $\begin{array}{l}-6.3 \\
{[-9.1,-3.6]}\end{array}$ & $\begin{array}{l}-6.4 \\
{[-9.2,-3.6]}\end{array}$ \\
\hline Best-Fit Line & Slope & $\begin{array}{l}0.39 \\
{[0.23,0.55]}\end{array}$ & $\begin{array}{l}0.37 \\
{[0.21,0.52]}\end{array}$ & $\begin{array}{l}0.37 \\
{[0.21,0.52]}\end{array}$ \\
\hline
\end{tabular}

Note: ${ }^{\dagger} p$-value of chi-squared test for normal distribution fit (larger values preferred). Values in brackets represent $95 \%$ confidence interval points.

values have intercepts that are statistically different from zero, and slopes that are statistically different from one (at the 0.05 level). Similarly, the slopes of the best-fit lines for the plots of the residuals versus the actual values are statistically different from one (at the 0.05 level). These results suggest that key explanatory variables (Section 3 ) have not been examined as part of the regressions. Additional predictor variables include those related to soil characteristics and other geologic features of the area, as well as attributes describing the building inventory and its ability to resist earthquake damages. Data on these variables, however, would be much more difficult to locate than data for the various predictor variables examined in this analysis (Table 2). This fact also has important implications for the potential users of our method, who would need to input these data into our estimating equation.

\section{Testing the Predictions of the Regression Models}

We tested the predictions from the Reduced-Form Models by applying them to a series of out-of-sample test cases. This involved comparing the damage predictions of the models with independent damage estimates from the literature, as well as for PAGER for four recent significant U.S. earthquakes. These four events (described in Table 7) took place in different geographic areas of the country during the years 2010 and 2011 (our dataset of 40 earthquakes extends only into the year 2008).

While the range of earthquake magnitude numbers across these four test events would appear to be narrow (magnitude values of 5.4 to 6.5 ), we note three things about this: (1) the magnitude is a logarithmic (not linear) scale; (2) earthquakes below magnitude 4.5 tend to cause relatively little property damage (unless they take place directly under a city or major infrastructure site); and (3) in most $(24 / 40=60 \%)$ of the earthquake events on which the Reduced-Form Models are based, the earthquake magnitude was between 5.4 and 6.5 (inclusive).

The low, average, and high estimated property damages for these out-of-sample test cases are presented in Table 7. For Test Case \#1, the range of estimated damages overlaps with, but also extends above the range of damage estimates from NGDC, but generally below the PAGER damage estimates (although the range of values is entirely contained within the 90th percentile range from PAGER). For Test Case $\# 2$, the Reduced-Form Model estimate is below (but adjoins) the NGDC damage range, and is considerably above the (extremely low) damages predicted by PAGER. In the case of Test Case \#3, the Reduced-Form Model estimates are above all of the literature estimates, and the range of PAGER estimates either completely covers or at the minimum overlaps with all of the other damage estimates. And finally, for Test Case \#4, PAGER's estimates are the largest (and its range of estimates the broadest), with the damage range from the Reduced-Form Model being generally in line with the other (non-PAGER) damages estimates.

Overall, the out-of-sample test results are promising, with the predictions of the Reduced-Form Models being in the general vicinity of the various other estimates from the literature. It appears that the Reduced-Form Model generates reasonable ballpark estimates, at least as evidenced by the reasonably good model fits (that is, adjusted R-squared values) and the results of the four out-of-sample test cases. Moreover, the damage estimates from the Reduced-Form Model can be produced nearly instantaneously after an earthquake event, as only two explanatory variables are required: income (readily available from U.S. Census data), and earthquake magnitude (estimates for which are available soon after an event occurs).

\section{Toward a Comprehensive Rapid Estimation Model}

The estimation of property damage is only a first step toward a thorough estimation of losses from natural disasters. Advances in hazard loss estimation were dominated by engineers through the mid-1990s, so it was natural that the focus would be on damage to the built environment, in addition to death and injury. However, there has been a growing awareness of the importance of what economists term the "flow" counterpart to the "stock" effects of property damage. These flows relate to changes in key economic indicators over time, including employment, Gross Domestic Product (GDP), and personal income, and are often characterized as "business interruption" (BI). In the last decade there have been several instances in which BI exceeded property damage, such as in the aftermath of 9/11 and the case of Hurricane Katrina, where flow losses are still accumulating since many for the areas hit have still not recovered. 
Table 7. Summary of four recent out-of-sample earthquake test cases applied to the Reduced-Form Model, with independent property damage estimates from the literature also given for comparison

\begin{tabular}{|c|c|c|c|c|c|c|c|}
\hline \multirow[t]{2}{*}{$\begin{array}{l}\text { Test } \\
\text { Case }\end{array}$} & \multirow{2}{*}{$\begin{array}{l}\text { Date/ } \\
\text { State/ } \\
\text { Earthquake } \\
\text { Magnitude }\end{array}$} & \multirow{2}{*}{$\begin{array}{l}\text { Exposure } \\
\text { (Population/ } \\
\text { Income/ } \\
\text { Census Tracts) }\end{array}$} & \multicolumn{2}{|l|}{$\begin{array}{l}\text { Independent (Literature) } \\
\text { Property Damage Estimates }\end{array}$} & \multicolumn{3}{|c|}{$\begin{array}{l}\text { Property Damage Estimates } \\
\text { from Reduced-Form Model }\end{array}$} \\
\hline & & & Description/Source & Value or Range ${ }^{\dagger}$ & $P D_{\text {low }}$ & $P D_{\text {average }}$ & $P D_{\text {high }}$ \\
\hline$\# 1$ & $\begin{array}{l}11 / 6 / 2011 \\
\text { Oklahoma } \\
5.7\end{array}$ & $\begin{array}{l}140,000 \\
\$ 2.8 \mathrm{~B} \\
35\end{array}$ & $\begin{array}{l}\text { NGDC damage categories / NGDC (2011) } \\
\text { PAGER / USGS (2012a) and Jaiswal and Wald (2011) }\end{array}$ & $\begin{array}{l}\$ 1.7-\$ 8.6 \mathrm{M} \\
\$ 18 \mathrm{M} \\
(\$ 1.8-\$ 180 \mathrm{M})\end{array}$ & $\$ 6.7 \mathrm{M}$ & $\$ 8.7 \mathrm{M}$ & $\$ 12 \mathrm{M}$ \\
\hline$\# 2$ & $\begin{array}{l}8 / 23 / 2011 \\
\text { Colorado } \\
5.4\end{array}$ & $\begin{array}{l}23,000 \\
\$ 520 \mathrm{M} \\
8\end{array}$ & $\begin{array}{l}\text { PAGER / USGS (2012a) and Jaiswal and Wald (2011) } \\
\text { NGDC damage categories / NGDC (2011) }\end{array}$ & $\begin{array}{l}\$ 2400 \\
(\$ 230-\$ 24,000) \\
\$ 1.7-\$ 8.6 \mathrm{M}\end{array}$ & $\$ 0.98 \mathrm{M}$ & $\$ 1.3 \mathrm{M}$ & $\$ 1.7 \mathrm{M}$ \\
\hline$\# 3$ & $\begin{array}{l}8 / 23 / 2011 \\
\text { Virginia } \\
5.8\end{array}$ & $\begin{array}{l}5.0 \mathrm{M} \\
\$ 200 \mathrm{~B} \\
1214\end{array}$ & $\begin{array}{l}\text { NGDC damage categories / NGDC (2011) } \\
\text { Governor of Virginia / Knittle (2011) } \\
\text { PAGER / USGS (2012a) and Jaiswal and Wald (2011) } \\
\text { EQECAT / Morello and Wiggins (2011) }\end{array}$ & $\begin{array}{l}\$ 1.7-\$ 8.6 \mathrm{M} \\
\$ 22 \mathrm{M} \\
\$ 60 \mathrm{M} \\
(\$ 6.0-\$ 610 \mathrm{M}) \\
\$ 200-\$ 300 \mathrm{M}\end{array}$ & $\$ 310 \mathrm{M}$ & $\$ 380 \mathrm{M}$ & $\$ 490 \mathrm{M}$ \\
\hline$\# 4$ & $\begin{array}{l}1 / 10 / 2010 \\
\text { California } \\
6.5\end{array}$ & $\begin{array}{l}135,000 \\
\$ 3.2 \mathrm{~B} \\
30\end{array}$ & $\begin{array}{l}\text { NGDC damage categories / NGDC (2011) } \\
\text { Governor of California / Stover (2010) } \\
\text { PAGER / USGS (2012a) and Jaiswal and Wald (2011) }\end{array}$ & $\begin{array}{l}\$ 8.6-\$ 41 \mathrm{M} \\
>\$ 44 \mathrm{M} \\
\$ 200 \mathrm{M} \\
(\$ 4.7 \mathrm{M}-\$ 8.1 \mathrm{~B})\end{array}$ & $\$ 23 \mathrm{M}$ & $\$ 32 \mathrm{M}$ & $\$ 44 \mathrm{M}$ \\
\hline
\end{tabular}

Note: ${ }^{\dagger}$ For PAGER, the point estimates are the averages, and the ranges represent the 5 th and 95 th percentile points. All values are in $2011 \$$.

At one point it was standard to refer to property damage as "direct economic impacts" and everything else as "indirect." However, even going back as far as the development of HAZUS in the mid-1990s, there was an awareness that both stock and flow losses had direct and indirect counterparts. Indirect property damage effects are exemplified by fires or toxic releases after earthquakes, for example. Indirect flow effects are the ripple, or multiplier, impacts on output, employment, and income stemming from direct BI. This framework is now commonplace in published literature (see, for example, Rose 2004) and major assessments of earthquake science and policy (NRC 2009).

Several approaches are used to estimate direct and indirect BI. The most straightforward and amendable to rapid estimation are to use factors that convert stock to flow losses, such as loss of function combined with down-time, which is at the core of HAZUS. Such factors can be readily programmed into models presented here. Even more basic, but not as accurate, would be the use of "output-capital" ratios for an economy as a whole or for various types of businesses/buildings. Indirect BI could be estimated by a full model, as in the case of the input-output module in HAZUS and the plan for GEM, or the use of simpler multipliers. There is some criticism of the use of I-O multipliers, as opposed to those that would be generated by the state of the art, but all too complex, modeling approach in this field - computable general equilibrium (CGE) analysis. CGE allows for non-linearities, such as those associated with input and import substitution, and hence typically generates lower multipliers.

However, the major factors affecting consequences from disaster are not these standard indirect BI multipliers but have more recently been identified by Rose (2009) and others as "resilience" in the case of natural hazards, and behavioral manifestations of fear associated with terrorist attacks or technological accidents. These have been shown to reduce losses by more than 50 percent in the case of resilience and to increase losses by an order of magnitude in the case of behavioral effects. Rose (2013) has identified factors that influence resilience and the fear factor, and can thus be used to adjust estimates by a set of appropriate scalars for rapid estimation.

\section{Conclusion}

This article has presented a further exploration into the potential of reduced-form models to estimate the economic impacts of earthquakes. Since earthquake events are complex phenomena - from both a natural science and human settlement system perspective - each major event ideally deserves extensive research attention. However, there is also a need for a practical tool that can generate immediate loss estimates for the purpose of dispatching short-run response assistance and marshaling resources for a longer-run recovery.

Our regression equation for property damage in significant U.S. earthquakes has shed additional light on this area of inquiry, demonstrating, in a transparent manner, which of several crude physical and economic predictor variables are best able to explain more than half of the variation in the property damages across a sample of 40 earthquakes. Our analysis also provides a basis for formulating analogous prediction equations for other hazard types, and reduced-form models may be especially beneficial in those hazard areas where generally less is known than for earthquakes. 
Improved earthquake estimation results can likely be obtained by identifying and quantifying additional variables to examine as part of the analysis. For example, additional physical (hazard-related) predictor variables might include peak ground acceleration and velocity, duration of the shaking, fault type, and length of the fault rupture. Additional exposure-related variables might include building type and age. Data for these variables exist, but would require time to collect, check, and refine, and our preliminary analysis indicates that these additional efforts would be justified.

\section{Acknowledgments}

This research was supported by the United States Department of Homeland Security through the National Center for Risk and Economic Analysis of Terrorism Events (CREATE) under Cooperative Agreement 2010-ST-061-RE0001. The authors thank Oswin Chan, Aaron Wolf, and Noah Dormady for their valuable assistance with various aspects of the data collection and analysis. We are also grateful to Susan Cutter, Michael Senn, and Keith Porter for comments on earlier versions of this article, as well as the comments from the editor and two anonymous reviewers. However, any opinions, findings, and conclusions or recommendations in this document are those of the authors and do not necessarily reflect views of the United States Department of Homeland Security or the University of Southern California.

\section{Notes}

i This pertains to Modified Mercalli Intensity (MMI) level VI or above (see discussion in Section 4.3).

ii To ensure accuracy, the results from applying this formula were checked against the latitude-longitude calculator available from the U.S. National Hurricane Center (NHC 2010).

iii This variable represents a simple interaction term. It is related to the more powerful concept of a ground motion prediction equation. Our approach is an alternative to these more complex types of equations, so as to make our approach more accessible to a broad set of users.

iv Both the SHELDUS property damage estimates and those gleaned from primary sources in our references are not always consistent in terms of coverage, as, for example, not always including content losses in addition to structural damage.

\section{References}

BEA (U.S. Bureau of Economic Analysis). 2012. Regional Economic Accounts. http://www.bea.gov/regional/.

Chan, L. S., Y. Chen, Q. Chen, L. Chen, J. Liu, W. Dong, and H. Shah. 1998. Assessment of Global Seismic Loss Based on Macroeconomic Indicators. Natural Hazards 17 (3): 269-283.

Dixon, P., B. Lee, T. Muehlenbeck, M. Rimmer, A. Rose, and G. Verikios. 2010. Effects on the U.S. of an H1N1 Epidemic: Analysis with a Quarterly CGE Model. Journal of Homeland Security and Emergency Management 7 (1): Article 7.
ECLAC (Economic Commission for Latin America and the Caribbean). 2003. Handbook for Estimating the Socio-Economic and Environmental Effects of Disasters. http://web.worldbank.org/WBSITE/ EXTERNAL/TOPICS/EXTURBANDEVELOPMENT/EXTDISMGMT/ 0, contentMDK:20196047 menuPK:1415429 pagePK:210058 piPK: 210062 theSitePK:341015,00.html.

Erdik, M., K. Sesetyan, M. B. Demircioglu, U. Hancilar, and C. Zulfikar. 2011. Rapid Earthquake Loss Assessment after Damaging Earthquakes. Soil Dynamics and Earthquake Engineering 31 (2): 247-266.

ESRI. 2010. ArcGIS Software Program. Version 10.0. Redlands, CA.

FEMA (U.S. Federal Emergency Management Agency). 2012. HAZUS Website. http://www.fema.gov/hazus.

GEM (GEM Foundation). 2011. OpenQuake Book. Version 0.1. Pavia, Italy. http://www.globalquakemodel.org/media/cms_page_media/79/ OpenQuake-Book_Version0.1.pdf.

Giesecke, J., W. Burns, A. Barrett, E. Bayrak, A. Rose, P. Slovic, and M. Suher. 2012. Assessment of the Regional Economic Impacts of Catastrophic Events: A CGE Analysis of Resource Loss and Behavioral Effects of a Radiological Dispersion Device Attack Scenario. Risk Analysis 32 (4): 583-600.

Huyck, C. K., H-C. Chung, S. Cho, M. Z. Mio, S. Ghosh, R. T. Eguchi, and S. Mehrotra. 2006. Centralized Web-Based Loss Estimation Tool: INLET for Disaster Response. In Nonintrusive Inspection, Structures Monitoring, and Smart Systems for Homeland Security, edited by A. A. Diaz, H. F. Wu, S. R. Doctor, and Y. Bar-Cohen. Proceedings of SPIE, Vol. 6178: Paper 61780B.

Jaiswal, K. S., and D. J. Wald. 2011. Rapid Estimation of the Economic Consequences of Global Earthquakes. U.S. Geological Survey Open-File Report 2011-1116. http://pubs.usgs.gov/of/2011/1116/.

Knittle, A. 2011. Virginia Quake's Aftermath Helps Officials in Oklahoma. The Oklahoman, November 17, 16A.

Loayza, N. V., E. Olaberria, J. Rigolini, and L. Christiaensen. 2012. Natural Disasters and Growth: Going Beyond the Averages. World Development 40 (7): 1317-1336.

MathWorks, Inc. 2011. Matlab Software Program. Version R2011b. Natick, MA.

Morello, C., and O. Wiggins. 2011. Region Tallies Earthquake Damage, Mostly Uninsured. Washington Post, August 24. http://www. washingtonpost.com/local/region-tallies-earthquake-damage-mostlyuninsured/2011/08/24/gIQAFdxScJ story.html.

NGDC (National Geophysical Data Center). 2011. Significant Earthquake Database. U.S. National Oceanic and Atmospheric Administration. http://www.ngdc.noaa.gov/nndc/struts/form? $\mathrm{t}=101650 \& \mathrm{~s}=$ $1 \& \mathrm{~d}=1$.

NHC (U.S. National Hurricane Center). 2010. Latitude/Longitude Distance Calculator. http://www.nhc.noaa.gov/gccalc.shtml.

NRC (National Research Council). 2009. National Earthquake Resilience: Research, Implementation and Outreach. Washington, DC: National Academy Press.

Rose, A. 2004. Economic Principles, Issues, and Research Priorities in Natural Hazard Loss Estimation. In Modeling the Spatial Economic Impacts of Natural Hazards, edited by Y. Okuyama and S. Chang, 13-36. Heidelberg: Springer.

Rose, A. 2009. A Framework for Analyzing and Estimating the Total Economic Impacts of a Terrorist Attack and Natural Disaster. Journal of Homeland Security and Emergency Management 6 (1): Article 4.

Rose, A. 2013. Macroeconomic Consequences of Terrorist Attacks: Estimation for the Analysis of Policies and Rules. In Benefit Transfer for the Analysis of DHS Policies and Rules, edited by V. K. Smith and C. Mansfield. Cheltenham, UK: Edward Elgar Publishing Company (forthcoming).

Rose, A., and S. B. Blomberg. 2010. Total Economic Impacts of a Terrorist Attack: Insights from 9/11. Peace Economics, Peace Science, and Public Policy 16 (1): Article 2.

Rose, A., D. Wei, and A. Wein. 2011. Economic Impacts of the ShakeOut Scenario. Earthquake Spectra: Special Issue on the ShakeOut Earthquake Scenario 27 (2): 539-557. 
Schumacher, I., and E. Strobl. 2011. Economic Development and Losses Due to Natural Disasters: The Role of Hazard Exposure. Ecological Economics 72: 97-105.

SHELDUS (Spatial Hazard Events and Losses Database for the United States, Version 9.0). 2011. Hazards and Vulnerability Research Institute, University of South Carolina. http://webra.cas.sc.edu/hvri/ products/sheldus.aspx.

Stover, C. W., and J. L. Coffman. 1993. Seismicity of the United States, 1568-1989 (revised). U.S. Geological Survey Professional Paper No. 1527. Washington, DC: U.S. Government Printing Office. http://pubs. er.usgs.gov/publication/pp1527.

Stover, F. 2010. Governor Estimates Earthquake Damages May Exceed $\$ 43$ Million. Humboldt Beacon (Fortuna, CA), January 21. http:// www.humboldtbeacon.com/news/ci 14238890.

Sue Wing, I., A. Rose, and A. Wein. 2010. Economic Impacts of the ARkStorm Scenario. In Overview of the ARkStorm Scenario, edited by K. Porter, A. Wein, C. Alpers, A. Baez, P. Barnard, J. Carter,
A. Corsi, J. Costner, D. Cox, T. Das, M. Dettinger, J. Done, C. Eadie, M. Eymann, J. Ferris, P. Gunturi, M. Hughes, R. Jarrett, L. Johnson, H. Dam Le-Griffin, D. Mitchell, S. Morman, P. Neiman, A. Olsen, S. Perry, G. Plumlee, M. Ralph, D. Reynolds, A. Rose et al. USGS Open-File Report 2010-1312.

U.S. Census Bureau. 2010. American Community Survey. http://www. census.gov/acs/www/.

U.S. Census Bureau. 2012a. Centers of Population for the 2010 Census. http://www.census.gov/geo/www/2010census/centerpop2010/ centerpop2010.html.

U.S. Census Bureau. 2012b. State and County QuickFacts. http:// quickfacts.census.gov/qfd/states/.

USGS (U.S. Geological Survey). 2012a. PAGER - Prompt Assessment of Global Earthquakes for Response. http://earthquake.usgs.gov/ earthquakes/pager/.

USGS (U.S. Geological Survey). 2012b. ShakeMaps. http://earthquake. usgs.gov/earthquakes/shakemap/.

Open Access This article is distributed under the terms of the Creative Commons Attribution License which permits any use, distribution, and reproduction in any medium, provided the original author(s) and source are credited. 